broken up into methyl iodide and into a sugar which resembles inosite, which is called Beta inosite. Struck with the analogies of this substance with the caoutchouc sugar, Combes has identified Beta pinite and matezite as the same sugar, and Beta inosite and matezodamzite as the same sugar." The following is a table of the physical constants of the various substances:

$\begin{array}{lcccc} & \text { Matezite. } & \text { B. Pinite. Matezodambose. B. Inosite. } \\ \text { Melting point ...... } & 18 r^{\circ} & 186^{\circ} .5 & 246^{\circ} & 246^{\circ} \\ \text { Rotatory power..... } & 66^{\circ} & 65^{\circ} . \% & 6 r^{\circ} .6 & 68^{\circ} .4\end{array}$

The rotatory powers are determined by solutions containing $2 \%$ of the material. From what precedes, it is evident that Beta pinite and Beta inosite are not new chemical compounds.

It is seen from the above data that we have in this exudation of the Pinus lambertiana a chemical body of the most remarkable and interesting properties. It is evident that the study of these properties has only been well commenced, and with the large quantities of material which are now at my disposal I hope at a subsequent time to add something more to our knowledge concerning it.

\title{
ANALYSIS OF A. PEKOE CEYLON TEA.
}

\section{By Joseph F. Geisler}

This sample of tea would be considered a curiosity by most people, inasmuch as its appearance is so different from that of the usual varieties of teas met with in commerce. It is a fine Pekoe Ceylon Tea, and its appearance shows it to consist of a mixture of small dark and yellow leaves, the latter predominating. These small leaves are tightly rolled into coils varying from $\frac{1}{4}$ to $\frac{1}{2}$ inch in length, the greater portion being about $\frac{5}{16}$ inch long, with an average diameter of about $\frac{1}{3} \mathrm{inch}$. The small, light, yellowish colored coils are completely uvered with hair, giving some a silvery appearance. 
When treated with boiling water the stemlike cylinders are shown to be thick leaves about i in. wide, of a leathery texture, very glossy on the inner surfuee, with prominent miltrib, the edges and midrib along the back of the leaf heing corered with hair. The small cylinders reveal themedres as leaves if in length and about $1, i$ in. wide, while the rery small ones are prineipally a mass of hairs.

The analysis of the tea gave the following data:

Moisture (loss by drying at $100,(1.) \ldots . .$. . b.20)

Soluble ash ... . . .... 3. $3 . \%$

Insoluble ash . . . . . . . . . . . $1.53 \%$

Total ash . . . . . . . . . . . . . . . . . 5.30\%

Theint . . . . . . . . . . . . . . . . .

Total tamin . . . . . . . . . . . . . . . . 2.89\%

Total cxtractive matter... . . . . . . . . . 43.40,

Insoluble leaf . . . . . . . . . . . . . . . . . 50.40\%

In the above data there is nothing particularly noteworthy excepting that the per cent. of tannin is very high.

An infusion of the tea was made by treating one (1) part of tea with 100 parts of boiling distilled wate: and allowing 10 minutes for the maceration. Lnder these conditions the tea yielded to water the following percentages:

Theine

$\therefore .44 \%$

Tannin.

1 1.. $19 \%$

'Total extractive matter

$33.25 \%$

Ash (total)

$3 .+4 \%$

Phosphoric acid $\left(\mathrm{P}_{2} \mathrm{O}_{5}\right)$ in ash

$0.18 \%$

The alkalinity of the ash was equivalent to 1.298 c of $\mathrm{K}_{2} 0$.

The infusion obtained was of a dark golden yellow color, and had a very agreeable aroma and pleasant taste. From the above it will be seen that the infusion took up $96.6 \%$ of the total theine $75.3 \%$ of the total tannin, and $91 \%$ of the soluble ash, data characteristic of a fine tea, as will be seen on comparison with analyses of teas of commerce reported by the author in 1889.*

* See Prescott's Organic Analysis, pp., 504-512. 